\title{
Infection of Porcine Circovirus 2 (PCV2) in Intestinal Porcine Epithelial Cell Line (IPEC-J2) and Interaction between PCV2 and IPEC-J2 Microfilaments
}

Mengfei Yan, Liqi Zhu and Qian Yang*

\begin{abstract}
Background: Porcine circovirus-associated disease (PCVAD) is caused by a small pathogenic DNA virus, Porcine circovirus type 2 (PCV2), and is responsible for severe economic losses. PCV2-associated enteritis appears to be a distinct clinical manifestation of PCV2. Most studies of swine enteritis have been performed in animal infection models, but none have been conducted in vitro using cell lines of porcine intestinal origin. An in vitro system would be particularly useful for investigating microfilaments, which are likely to be involved in every stage of the viral lifecycle.

Methods: We confirmed that PCV2 infects the intestinal porcine epithelial cell line IPEC-J2 by means of indirect immunofluorescence, transmission electron microscopy, flow cytometry and qRT-PCR. PCV2 influence on microfilaments in IPEC-J2 cells was detected by fluorescence microscopy and flow cytometry. We used Cytochalasin $D$ or Cucurbitacin E to reorganize microfilaments, and observed changes in PCV2 invasion, replication and release in IPEC-J2 cells by qRT-PCR.
\end{abstract}

Results: PCV2 infection changes the ultrastructure of IPEC-J2 cells. PCV2 copy number in IPEC-J2 cells shows a rising trend as infection proceeds. Microfilaments are polymerized at $1 \mathrm{~h}$ p.i., but densely packed actin stress fibres are disrupted and total F-actin increases at 24, 48 and $72 \mathrm{~h}$ p.i. After Cytochalasin D treatment, invasion of PCV2 is suppressed, while invasion is facilitated by Cucurbitacin E. The microfilament drugs have opposite effects on viral release.

Conclusion: PCV2 infects and proliferates in IPEC-J2 cells, demonstrating that IPEC-J2 cells can serve as a cell intestinal infection model for PCV2 pathogenesis. Furthermore, PCV2 rearranges IPEC-J2 microfilaments and increases the quantity of F-actin. Actin polymerization may facilitate the invasion of PCV2 in IPEC-J2 cells and the dissolution of cortical actin may promote PCV2 egress.

Keywords: PCV2, Intestinal epithelial cell, Microfilaments

\footnotetext{
* Correspondence: zxbyq@njau.edu.cn

College of Veterinary Medicine, Nanjing Agricultural University, Nanjing 210095, PR China
} 


\section{Introduction}

Porcine circovirus (PCV), a member of the family Circoviridae, is the smallest known non-enveloped, single-stranded, circular DNA virus [1]. Two types of PCV are now recognized. PCV1, originally identified as a contaminant of the porcine kidney cell line PK-15, is considered to be nonpathogenic [2-4] although it can replicate efficiently and produce pathology in the lungs of porcine foetuses [5]. PCV2 is associated with porcine circovirus-associated disease (PCVAD), which was first described in the early 1990s and has since emerged as an economically damaging disease worldwide [6]. PCVAD causes diverse pathologies, including porcine multisystemic wasting syndrome (PMWS), porcine dermatitis and nephropathy syndrome (PDNS), porcine respiratory disease complex (PRDC), reproductive failure, acute pulmonary edema (APE), and other diseases [7-11]. This article focuses on enteritis, another important clinical manifestation [12-14]. The oronasal route is considered the most likely route of PCV2 infection [15] but the key mechanisms involved in infection, especially the invasion, replication and release of PCV2, have not been studied in vitro.

Actin is crucial for many kinds of important cellular processes including cell division, polarity, motility, uptake of nutrients and intracellular transport. Actin occurs in two basic forms, monomeric or globular actin (G-actin) and filamentous actin (F-actin). Cell biologists have used smallmolecule modulators of actin to manipulate the cytoskeleton. For example, Cytochalasin D (CytD) inhibits actin polymerization, blocking the addition of new monomers to actin filaments by binding to the positive end of actin filaments [16]. Cucurbitacin $\mathrm{E}$ is a potent inhibitor of actin depolymerization, binding specifically to F-actin by forming a covalent bond at residue Cys257 [17].

Microfilaments formed by F-actin fibres present both a powerful barrier and a potential weakness for viral invasion. Interactions between influenza virus and the actin cytoskeleton have been observed throughout the virus life cycle, including entry [18], intracellular trafficking [19] and egress [20]. PCV2 DNA impairs actin polymerization in plasmacytoid dendritic cells (DCs) and endocytosis in monocytederived DCs [21], potentially explaining PCV2-induced immunosuppression [22]. PCV2 internalization in porcine kidney (PK-15), swine kidney (SK) and swine testicle (ST) epithelial cells is mediated by actin and Rho-GTPase [23]. Here we examine the link between PCV2 and microfilaments in the intestinal porcine epithelial cell line, IPEC-J2, and develop an intestinal cell infection model for investigating $\mathrm{PCV} 2$ pathogenesis.

\section{Materials and methods}

Cells and virus

IPEC-J2 cell lines free from Porcine circovirus (Guangzhou Jennio Biotech Co.,Ltd., China) were used in this study.
IPEC-J2 cells were cultured in Dulbecco's Modified Eagle's Medium nutrient mixture F-12 (DMEM/F-12 from Life Technologies, USA) supplemented with $5 \%$ fetal bovine serum (FBS, Life Technologies, USA), 16 mM HEPES (Life Technologies, USA) and $5 \mathrm{ng} / \mathrm{mL}$ epidermal growth factor (EGF, BD Biosciences, Germany), and incubated in an atmosphere of $5 \% \mathrm{CO}_{2}$ at $37^{\circ} \mathrm{C}$ [24]. Cells were routinely seeded at a density of $2 \times 10^{5} / \mathrm{mL}$ in plastic tissue culture flasks $\left(25 \mathrm{~cm}^{2}\right.$ flasks, Corning, USA) and passaged every 3-4 days for a maximum of 20 times. In our experiments, IPEC-J2 cells were grown on 6- or 24-well plastic tissue culture plates (Corning, USA) at a density of $3 \times 10^{5} /$ well or $1.5 \times 10^{6} /$ well, respectively.

PCV2 strain WG09 (GenBank accession no. GQ845027) was kindly provided by Professor Ping Jiang [25]. The virus stock was a fourth-passage cell culture prepared in PK-15 cells with a titer of $10^{6} \mathrm{TCID}_{50} / \mathrm{ml}$.

\section{Virus titration by IFA}

To determine the infectious titer of PCV2 virus stock in IPEC-J2 cells, cells were cultivated on coverslips in 24-well tissue culture plates. Virus stock was serially diluted 10-fold in DMEM/F-12, and each dilution was inoculated onto 10 wells containing IPEC-J2 cell monolayers. Wells containing mock infected cells were included as controls. Infected cells were fixed at 3 days postinoculation with $4 \%$ paraformaldehyde in $0.01 \mathrm{M}$ PBS buffer at room temperature for $20 \mathrm{~min}$. After washing with PBS buffer, infected cells were incubated with a 1:500diluted PCV2 capsid protein rabbit polyclonal antibody (Global Biotech, USA) at $37^{\circ} \mathrm{C}$ for $1 \mathrm{~h}$. The cells were then washed three times with PBS buffer and incubated with a DyLight488 goat anti-rabbit IgG secondary antibody (Liankebio, China) at $37^{\circ} \mathrm{C}$ for $45 \mathrm{~min}$. Finally, the cells were washed, stained 5 min with DAPI (diluted 1000-fold, Life Technologies, USA) rinsed again then mounted on microslides and examined under a fluorescence microscope (ZEISS Observer.Z1, Germany). Five microscope fields per coverslip were selected to calculate the $50 \%$ tissue culture infective dose $\left(\mathrm{TCID}_{50}\right)$ per $\mathrm{ml}$.

\section{Transmission electron microscopy}

IPEC-J2 cells were grown on 6-well tissue culture plates and infected with PCV2 at $3 \times 10^{2.5} \mathrm{TCID}_{50} / \mathrm{ml}$ for 1 and $48 \mathrm{~h}$. Wells containing mock infected cells were included as controls. Cells at various times were fixed with $2.5 \%$ glutaraldehyde in $0.1 \mathrm{M}$ PBS buffer for $3 \mathrm{~h}$ at $4^{\circ} \mathrm{C}$. Subsequently, samples were processed as described [26] and analyzed by using a Hitachi-7650 transmission electron microscope (TEM, Japan) at $120 \mathrm{kV}$.

\section{Flow cytometry}

IPEC-J2 cells were grown on 6-well tissue culture plates and infected with PCV2 at $3 \times 10^{2.5} \mathrm{TCID}_{50} / \mathrm{ml}$ for 1,24 , 
48 and $72 \mathrm{~h}$. Wells containing mock infected cells were included as controls. Cells at various times were harvested and cultured at $37^{\circ} \mathrm{C}$ with a PCV2 capsid protein rabbit polyclonal antibody and a DyLight 488 goat antirabbit IgG secondary antibody as described above. After antibody incubation, cells were washed and the viral mean fluorescence intensity (MFI) was determined using a FACS Calibur flow cytometer (BD, USA). For flow cytometric analyses, three replicas are presented.

\section{Viral growth curve by qRT-PCR}

To determine PCV2 virus loads in cells and supernatants collected from PCV2-infected IPEC-J2 cells, cells were grown on 24-well tissue culture plates and infected with PCV2 at $3 \times 10^{2.5} \mathrm{TCID}_{50} / \mathrm{ml}$ for $6,12,24,48,72$, 96 and $120 \mathrm{~h}$. Wells containing mock infected cells were included as controls. The supernatants at various times post-infection were transferred directly into centrifuge tubes, while cells were harvested by trypsin digestion and then transferred into centrifuge tubes. The volume of both supernatants and trypsin-treated cells was $200 \mu \mathrm{l}$. Viral DNAs were isolated from supernatants or cells using a Mag-Bind Viral DNA/RNA Kit (Omega Bio-Tek, USA) according to the manufacturer's instructions. The DNAs extracted from the cells and/or cell culture supernatants were resuspended in $50 \mu \mathrm{l}$ of DNase-, RNase-, and proteinase-free water.

For PCR, primers containing restriction sites for Hind III and Kpn I were designed to amplify a 447-bp ORF2 fragment of PCV2 (sense primer 5'-GTCCTGGTCG TATTTACTGTTT-3'; antisense primer $5^{\prime}$-GTCAGAAC GCCCTCCTG-3'). The amplicon was cloned into the pMD ${ }^{\circ} 19-T$ Simple Vector (Takara, Japan). The recombinant plasmid was purified and quantitated by optical density $\left(\mathrm{OD}_{260}\right)$. Ten-fold dilutions were prepared to provide $10^{9}-10^{2}$ plasmids per $2 \mu \mathrm{l}$ sample for PCR. The dilutions were stored at $-20^{\circ} \mathrm{C}$, while plasmid stocks were stored at $-70^{\circ} \mathrm{C}$.

qPCR was performed in a $25 \mu \mathrm{l}$ reaction volume using an ABI 7500 thermocycler (Applied Biosystems, USA). For supernatant and cell samples, $2 \mu \mathrm{l}$ of the DNA eluate was used as template. The real-time PCR procedure followed the protocol provided with $\mathrm{SYBR}^{\circ}$ Premix Ex $\mathrm{Taq}^{\text {Tw }}$ GC (Takara, Japan). Three concentrations of recombinant plasmid $\left(10^{8}, 10^{5}\right.$, and $10^{2}$ copies per sample) were included in each run as positive controls, and were used derive the standard curve for quantitation of PCV2 DNA in supernatant and cell samples. Each run included two negative controls (no template).

\section{Microfilament changes by fluorescence microscopy}

IPEC-J2 cells were grown on coverslips in 24-well tissue culture plates and infected with PCV2 at $3 \times 10^{2.5}$ $\mathrm{TCID}_{50} / \mathrm{ml}$ for $1,24,48$ and $72 \mathrm{~h}$. Wells of mock infected cells were included as controls. Cells were treated following the protocol recommended for Alexa Fluor 488 phalloidin (Life Technologies, USA). DAPI (Life Technologies, USA) was used as a nuclear counterstain. Finally, cells were mounted on microslides and fluorescence images were recorded using a ZEISS Observer.Z1.

\section{Microfilament changes by FCM}

IPEC-J2 cells were cultivated on 6-well tissue culture plates and infected with PCV2 at $3 \times 10^{2.5} \mathrm{TCID}_{50} / \mathrm{ml}$ for $1,24,48$ and $72 \mathrm{~h}$. Wells of mock infected cells were included as controls. Cells at various times were harvested and cultured with Alexa Fluor 488 phalloidin as described in section 2.6. After phalloidin incubation, cells were washed and the F-actin MFI was analyzed on a FACS Calibur flow cytometer (BD, USA). For flow cytometric analyses, three replicas are presented.

\section{Viral lifecycle change after CytD/CuE by RT-PCR}

Microfilament drug stocks were prepared in DMSO at concentrations of $4 \mathrm{mM}$ for CytD (Life Technologies, USA) and $27 \mathrm{mM}$ for $\mathrm{CuE}$ (Sigma-Aldrich, USA). Different dilutions were assessed to determine concentrations with maximal effects on microfilaments without losses in cell viability, based on instructions accompanying the cell counting Kit-8 (Beyotime, China). In all experiments the concentration of CytD was $2 \mu \mathrm{M}$ and the concentration of $\mathrm{CuE}$ was $50 \mathrm{nM}$. Drugs were diluted to final concentrations in cell culture medium and added to infected IPEC-J2 cells. Specifically, for investigating changes due to viral invasion, cells were first treated with $\mathrm{CytD} / \mathrm{CuE}$ for $2 \mathrm{~h}$, then infected with PCV2 at $3 \times 10^{2.5} \mathrm{TCID}_{50} / \mathrm{ml}$. After $1 \mathrm{~h}$, cells were harvested for quantitation of PCV2 DNA. For investigating changes in viral replication and release, cells were first infected with PCV2 at $3 \times 10^{2.5} \mathrm{TCID}_{50} / \mathrm{ml}$ for $1 \mathrm{hr}$, then treated with $\mathrm{CytD} / \mathrm{CuE}$, these cells and supernatants were harvested at 24, 48 and 72 h p.i. PCV2 DNA was quantitated in both cells and supernatants for replication, but in supernatants only for release. Infected cells untreated with $\mathrm{CytD} / \mathrm{CuE}$ were included as controls. The quantitation of PCV2 DNA was accomplished as described earlier.

\section{Statistical analysis}

Statistical analysis was performed using Statistical Program for Social Sciences (SPSS) 16.0. Significance was determined by Analysis of Variance (ANOVA). A $P$ value less than 0.05 was considered to be significant, and less than 0.01 was considered to be highly significant.

\section{Results}

\section{Viral appearance in cells}

The infectious titer of the PCV2 virus stock prepared from IPEC-J2 cells was determined to be $10^{4.5} \mathrm{TCID}_{50} / \mathrm{ml}$. In a 
survey using TEM, virus appeared near microvilli of differing lengths and widths at $1 \mathrm{~h}$ p.i. (Figure 1B; compare uninfected cells in Figure 1A) and in cells at $48 \mathrm{~h}$ p.i. (Figure 1C and D). Mitochondria increased in size and became more spherical, mitochondrial matrixes became shallower, and cristae were shortened and reduced in number. Mitochondrial vacuolization was also observed at 48 h p.i. (Figure 1D).

\section{Viral proliferation in cells}

Fluorescently labeled viruses in PCV2-infected cells were detected using FCM. As shown in Figure 1E, viral MFI increased from 1 to $72 \mathrm{~h}$ p.i. Similarly, total viral DNAs detected by qRT-PCR in PCV2-infected cells and supernatants increased from 6 to $96 \mathrm{~h}$ p.i., although DNA decreased at $120 \mathrm{~h}$ p.i. (Figure 1F). These data demonstrate that PCV2 can proliferate in IPEC-J2 cells.

\section{Microfilament changes by virus}

To determine whether PCV2 affects F-actin during infection, IPEC-J2 cells were fluorescently stained at different times post infection and examined by fluorescence microscopy. Uninfected IPEC-J2 cells were typically cobblestone in shape with clear boundaries, and contained intracytoplasmic microfilaments scattered in a parallel formation. In contrast, microfilaments in infected cells were distributed and granular in appearance at $1 \mathrm{~h}$ p.i., although weak parallel patterns could be discerned in some cases. At $24 \mathrm{~h}$ p.i., perinuclear microfilaments were greatly reduced and cell boundaries became clear in the PCV2infected cells. Infected cells at $48 \mathrm{~h}$ p.i. were similar to those at $24 \mathrm{~h}$ p.i. At $72 \mathrm{~h}$ p.i., microfilament disorganization under the plasma membrane was apparent, but some reorganization could be observed below the plasma membrane in the infected cells (Figure 2). Changes in total cellular F-actin in PCV2-infected cells were also determined using FCM. As shown in Figure 3, total F-actin in both infected and uninfected cells decreased at 24 and $48 \mathrm{~h}$ p.i. and then increased at $72 \mathrm{~h}$ p.i., compared to levels at $1 \mathrm{~h}$ p.i. However, the MFI of F-actin in infected cells was higher than the MFI of F-actin in uninfected cells at all observed time points. The microscopic evaluation and F-actin assays demonstrate that PCV2 influences microfilaments both morphologically and quantitatively in IPEC-J2 cells.

\section{Viral life cycle changes in response to $\mathrm{CytD} / \mathrm{CuE}$}

To investigate the relationship between microfilament structure and the PCV2 life cycle, IPEC-J2 cells were treated with one of two chemical inhibitors of F-actin dynamics, CytD or CuE. In the first experiment, cells were pretreated with inhibitor for two hours and then
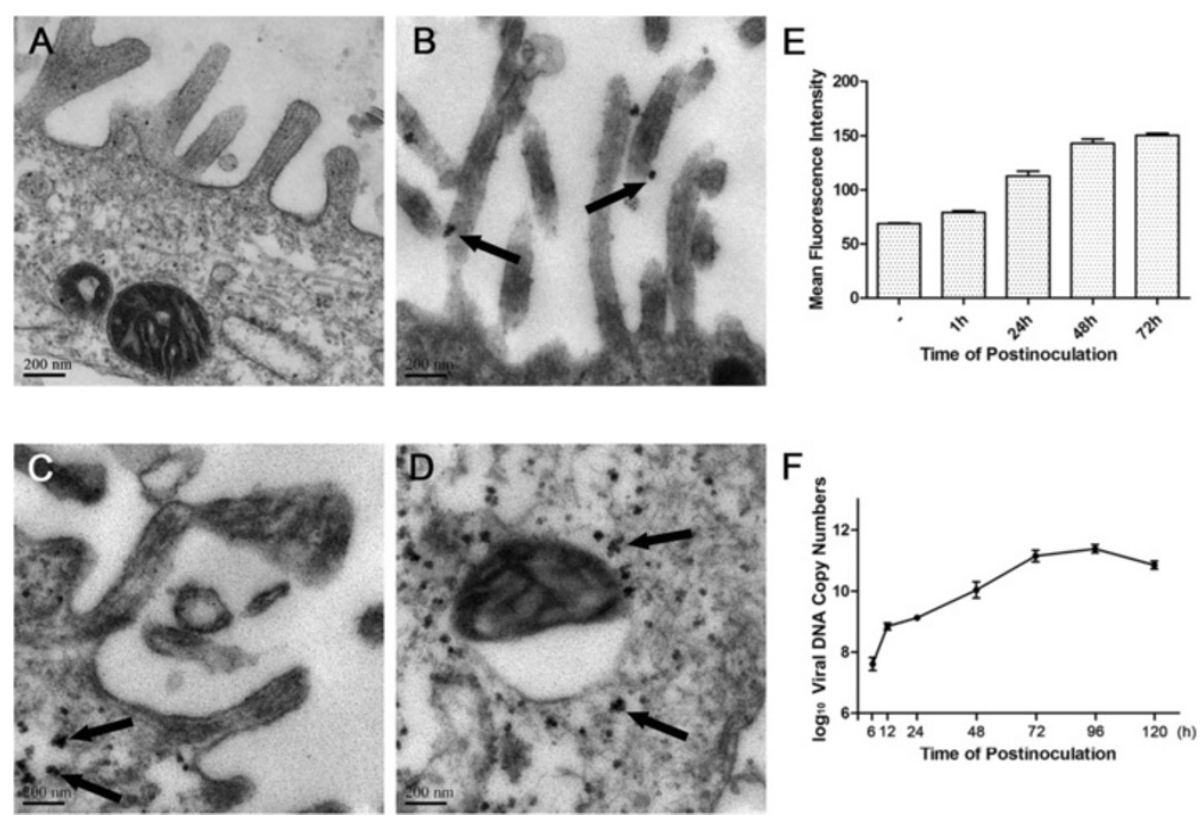

Figure 1 Infection of PCV2 in IPEC-J2 Cells. (A, B, C and D). Electron microscopic analysis of ultrathin sections of IPEC-J2 cells either without PCV2 (A , control ), or infected with PCV2 at $3 \times 10^{2.5} \mathrm{TCID}_{50} / \mathrm{ml}$ for $1 \mathrm{~h}$ (B) and $48 \mathrm{~h}$ (C and D). Black arrows indicate virus. (E) Flow cytometry analysis of mean fluorescence intensity of PCV2 in IPEC-J2 cells either without PCV2 (-, control ), or infected with PCV2 at $3 \times 10^{2.5} \mathrm{TCID} \mathrm{D}_{50} / \mathrm{ml}$ for 1, 24, 48 and 72 h. PCV2 was detected using a PCV2 capsid protein rabbit polyclonal antibody and a DyLight488 goat anti-rabbit IgG secondary antibody. Values are means \pm SEM for three separate experiments. (F) Viral growth curve. IPEC-J2 cells were infected with PCV2 at $3 \times 10^{2.5} \mathrm{TCID}_{50} / \mathrm{ml}$. Supernatants and cells were harvested at 6, 12,24,48,72, 96 and $120 \mathrm{~h}$ p.i. To obtain cell-associated infectivity, viral DNAs were quantitated by qRT-PCR assay. Values are means \pm SEM for three separate experiments. 


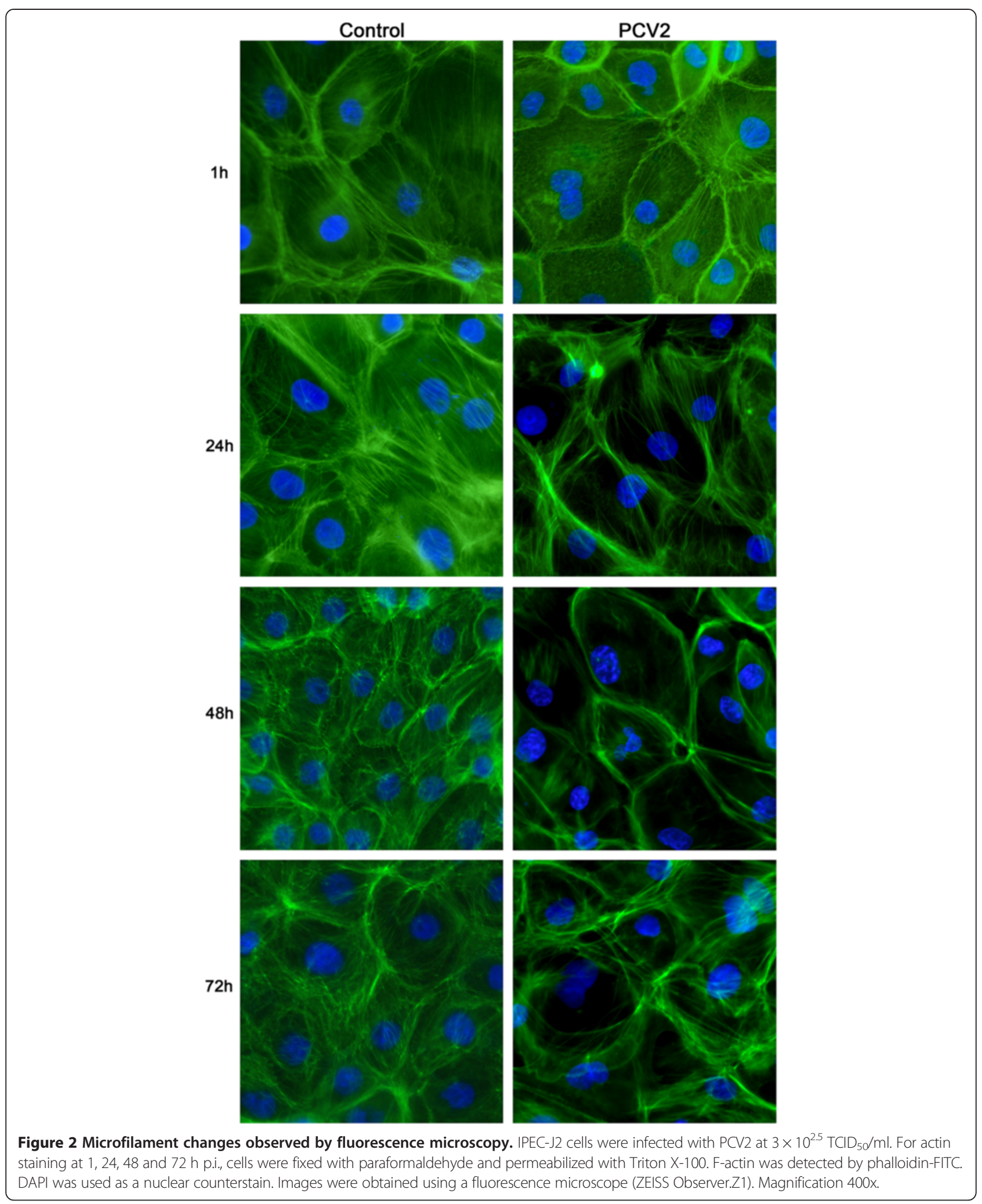

infected with PCV2 for a short period to detect changes affecting viral invasion. At $1 \mathrm{~h}$ p.i. the viral copy number in CytD-treated cells decreased $(P<0.01)$ relative to untreated controls, while copy number in CuE-treated cells increased $(P<0.01)$ (Figure $4 \mathrm{~A})$. In a second experiment, cells were infected with PCV2 and then treated 


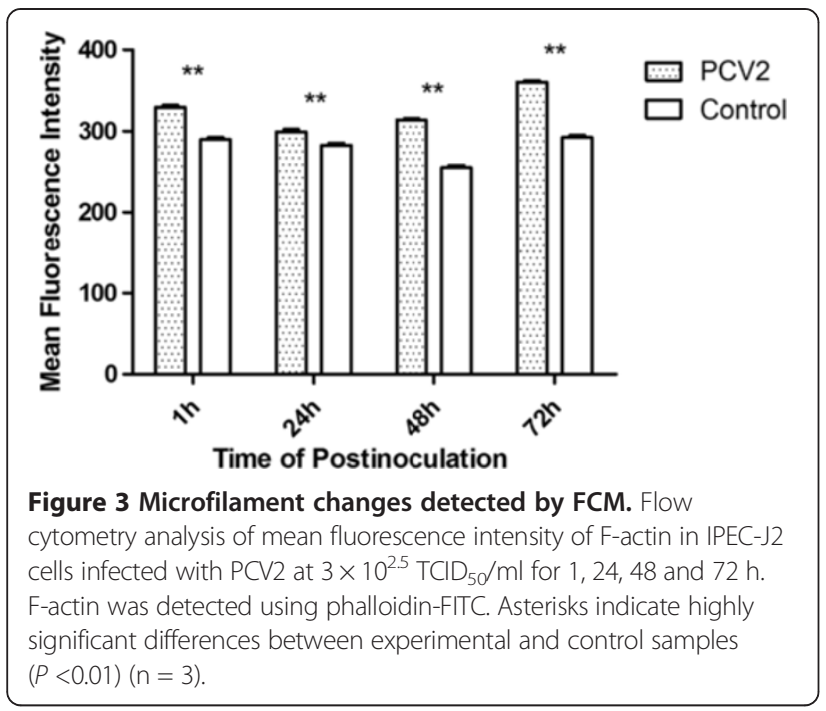

with inhibitor $1 \mathrm{~h}$ p.i. to examine impacts on viral replication. Viral copy number in CytD-treated cells increased significantly $(P<0.01)$ at 24 and 48 h p.i. (Figure 4B). CuE treatment resulted in copy number increases as well $(P<0.01)$ at 24,48 and 72 h p.i. (Figure $4 B)$. In the final experiment, cells were treated as described in experiment 2 , but viral copy number was assayed in the culture medium after cells had been removed. Viral copy number increased $(P<0.01)$ at 24,48 and 72 h p.i. after CytD treatment (Figure 4C). In contrast, viral copy number decreased $(P<0.01)$ at $24 \mathrm{~h}$ p.i. after $\mathrm{CuE}$ treatment (Figure 4C).

\section{Discussion}

Enteritis is one manifestation of PCV2 infection. The clinical signs are diarrhoea, which is initially yellowish but progresses to black, accompanied by retardation of growth [8]. The most consistent and predominant histopathological features of PCV2-associated enteritis are granulomatous inflammation and lymphoid depletion in the Peyer's patches in the small and large intestines, and the presence of intra-cytoplasmic inclusion bodies [12]. Investigations of enteritis in swine have been performed in animal infection models, but thus far none have been conducted in vitro using porcine intestinal cell lines. We therefore selected the IPEC-J2 cell line, a permissive host for enteric pathogens with typical epithelial cell characteristics [27] for this study.

PCV2 infection causes ultra-structural changes in the mitochondria, affecting both overall shape and internal features, including matrix and cristae morphology. The diameter of porcine circovirus particles is about $17 \mathrm{~nm}$, and virus particles with these dimensions were observed by TEM in infected IPEC-J2 cells. Immunofluorescence confirmed the presence of PCV2 inclusions as well.
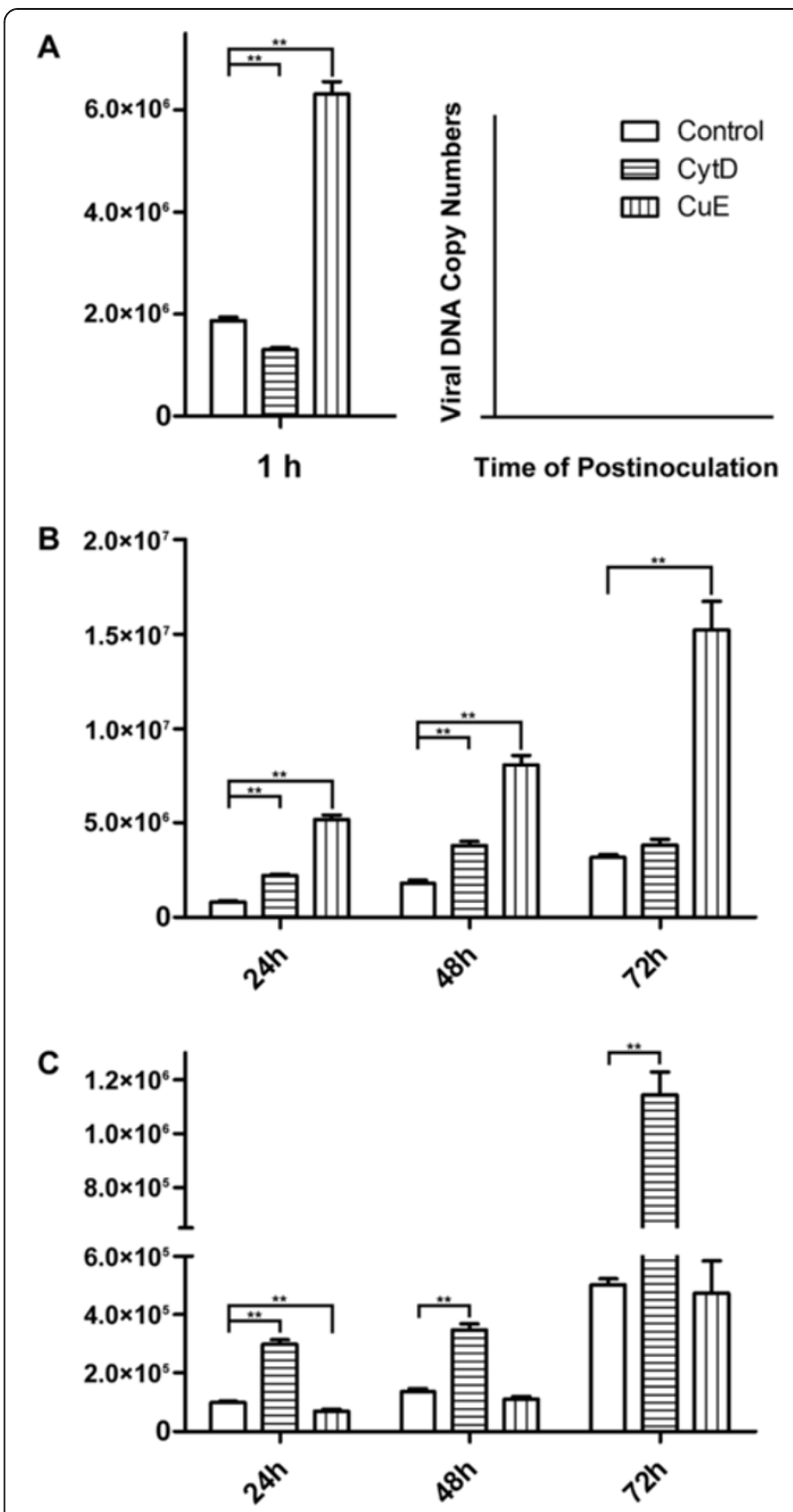

Figure 4 Viral lifecycle changes after CytD/CuE treatment.

(A) Effect of microfilament depolymerisation and polymerization on viral invasion. To modify microfilaments, IPEC-J2 cells were treated with CytD or CuE for $2 \mathrm{~h}$. Cells were then infected with PCV2 at $3 \times 10^{2.5} \mathrm{TCID}_{50} / \mathrm{ml}$ for $1 \mathrm{~h}$ and harvested. Viral DNAs were quantitated by qRT-PCR. (B) Effect of microfilament depolymerisation and polymerization on viral replication. IPEC-J2 cells were infected with PCV2 at $3 \times 10^{2.5} \mathrm{TCID}_{50} / \mathrm{ml}$. To modify microfilaments, CytD or CuE was added at $1 \mathrm{~h}$ p.i., and supernatants and cells were harvested at 24, 48 and $72 \mathrm{~h}$ p.i. respectively. Viral DNAs in supernatants and cells were quantitated by qRT-PCR assay. (C) Effect of microfilament depolymerisation and polymerization on viral release. IPEC-J2 cells were infected with PCV2 at $3 \times 10^{2.5} \mathrm{TCID}_{5} / \mathrm{ml}$. To modify microfilaments, CytD or CuE was added at $1 \mathrm{~h}$ p.i., and supernatants were harvested at 24,48 and $72 \mathrm{~h}$ p.i. respectively. Viral DNAs in supernatants were quantitated by qRT-PCR. Asterisks above columns indicate highly significant differences between groups $(P<0.01)(n=3)$. 
We demonstrated conclusively that PCV2 can infect IPEC-J2 cells. PCV2 DNAs in infected IPEC-J2 cells increase steadily from 6 to $96 \mathrm{~h}$ p.i. but decrease at $120 \mathrm{~h}$ p.i., presumably due to the depletion of nutrients in the medium. Circoviruses depend on cellular polymerases for their replication [28], and PCV genomic DNA replication depends on cellular enzymes expressed during the S-phase of the host cell cycle [29].

Within the cell, actin filaments can be arranged to form diverse structures. Stress fibres are large assemblies of actin filaments that can span the length of the cell (Figure 5). Cortical actin is a loosely organized network of actin filaments associated with the plasma membrane (Figure 5). Actin filaments also can be organized to produce a range of cellular extensions [30]. Viral infection is known to induce cytoskeletal reorganization. In this study, we found that PCV2 infection was accompanied by changes in microfilament organization at various time points post infection, possibly due to the production of new actin-based structures. Total F-actin in infected cells decreased at 24 and $48 \mathrm{~h}$ p.i. and then increased at $72 \mathrm{~h}$ p.i., compared to $1 \mathrm{~h}$ p.i. Cytoskeletal changes, monitored using microscopy, occurred in parallel, with a reduction in perinuclear microfilaments in PCV2-infected cells at 24 and $48 \mathrm{~h}$ p.i. At $72 \mathrm{~h}$ p.i., microfilaments were disorganized at the cell border but appeared to be reorganized in adjacent regions, suggesting that new actin-based structures had been produced. Since cells transition from

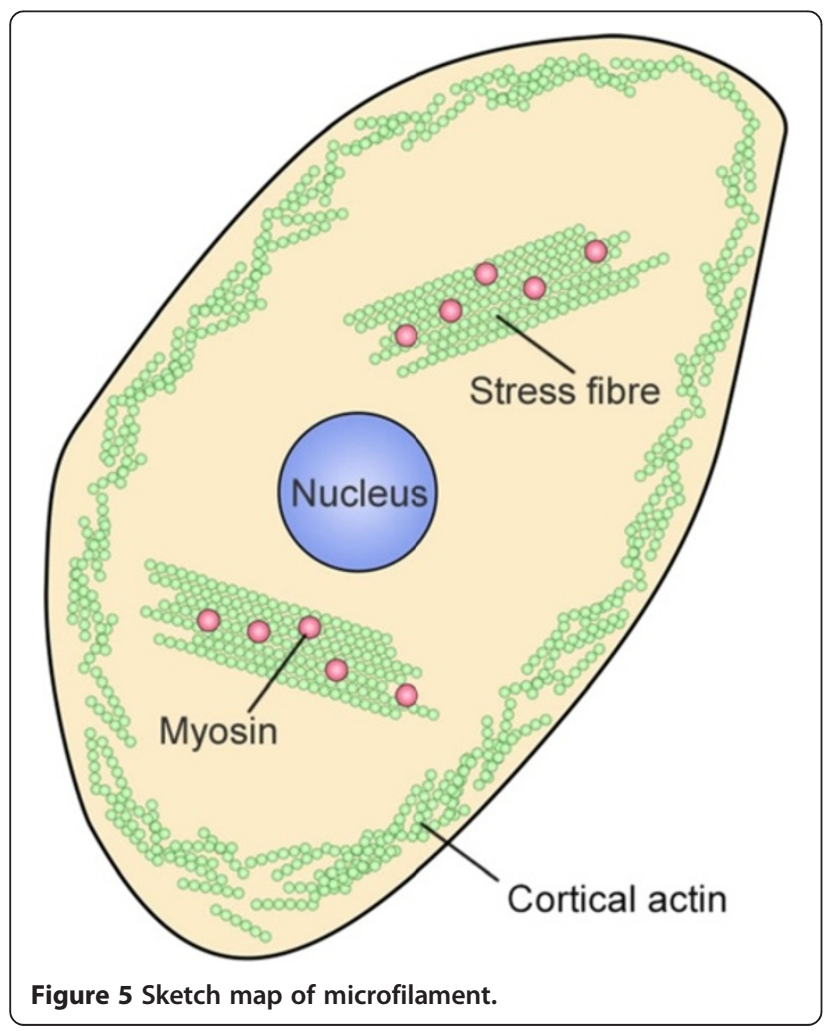

normal to pathological states during viral infection, drastic changes in the regulation of cell signaling, cytoskeletal structure, and cell cycle are to be expected.

For viral invasion to occur, the physical barrier presented by cortical actin must be overcome. Virus binding initiates signaling events that change the cell surface and activate endocytosis [31], in which cytoskeletal actin plays an important role. Existing actin filaments undergo severing and depolymerization, while new actin filaments are polymerized from monomeric actin subunits and by branching from existing filaments [32]. CytD, which inhibits actin polymerization, strongly reduced PCV2 incursion in IPECJ2 cells. In contrast, $\mathrm{CuE}$ treatment, which inhibits actin depolymerization, increased PCV2 invasion. These results indicate that actin polymerization may be required during PCV2 infection in IPEC-J2 cells. A similar requirement has been shown during PCV2 infection of monocytes/ macrophages [33] and internalization into DCs [34].

Viral replication increased in both $\mathrm{CytD}$ and $\mathrm{CuE}$ treated cells. Interestingly, CytD treatment enhanced viral replication while decreasing viral entry. This may be due to the fact that CytD not only disrupts actin microfilaments but also activates p53-dependent pathways, causing arrest of the cell cycle at the G1-S transition [35]. During the G1-S transition, chromosomes are duplicated by the cell, and PCV genomic DNA replication depends on cellular enzymes that are expressed during this period [29].

After $\mathrm{CuE}$ treatment, PCV2 replication increased significantly. Although a corresponding increase in viral release might be expected, our data showed no significant change in release compared with the control group. Currently, little is known about the egress of non-enveloped viruses from infected cells, commonly thought to occur as a virus burst after cell disintegration. Vaccinia virus (VV)-infected cells exhibit a unique phenotype involving changes in the actin cytoskeleton that are required for the spread of the infection [36]. In this system, CytDmediated dissolution of cortical actin restores viral movement to the cell periphery in the absence of functional F11 (coded by the gene F11L), supporting the conclusion that $\mathrm{VV}$ reorganizes the cortical actin network to allow virus access to the plasma membrane. Our study found that PCV2 infection resulted in a loss of actin stress fibres and production of new actin-based structures at later stages of infection. We surmise that CytD treatment facilitates this process, causing CytD-treated cells to release more virus than untreated cells. In contrast, cells treated with $\mathrm{CuE}$ exhibit the opposite effect. Therefore, the dissolution of cortical actin may be required during PCV2 egress from IPEC-J2 cells.

\section{Conclusions}

PCV2 not only infects IPEC-J2 cells but also proliferates in them, demonstrating that IPEC-J2 cells can serve as 
an intestinal cell infection model for studying PCV2 pathogenesis. When PCV2 invades IPEC-J2 cells, it causes actin polymerization, which may be conducive to viral invasion. At the replication and release phase, PCV2 appears to induce a reduction in stress fibres and production of new actin structures, leading us to conclude that the remodeling of cortical actin may facilitate viral release.

\section{Competing interests}

The authors declare that they have no competing interests.

\section{Authors' contributions}

MY participated in the design of this study, carried out all the studies, performed the statistical analysis and drafted the manuscript. LZ participated in the design of this study and performed partial infection experiments. QY conceived of the study and participated in its coordination. All authors read and approved the final manuscript.

\section{Acknowledgments}

This study was supported by project 31372465 from the National Science Grant of China.

Received: 28 May 2014 Accepted: 28 October 2014

Published online: 19 November 2014

\section{References}

1. Todd D, Niagro F, Ritchie B, Curran W, Allan G, Lukert P, Latimer K, Steffens W III, McNulty M: Comparison of three animal viruses with circular single-stranded DNA genomes. Arch Virol 1991, 117:129-135.

2. Allan G, McNeilly F, Cassidy J, Reilly G, Adair B, Ellis W, McNulty M: Pathogenesis of porcine circovirus; experimental infections of colostrum deprived piglets and examination of pig foetal material. Vet Microbiol 1995, 44:49-64.

3. Krakowka S, Ellis J, Meehan B, Kennedy S, McNeilly F, Allan G: Viral wasting syndrome of swine: experimental reproduction of postweaning multisystemic wasting syndrome in gnotobiotic swine by coinfection with porcine circovirus 2 and porcine parvovirus. Vet Pathol Online 2000, 37:254-263.

4. Tischer I, Rasch R, Tochtermann G: Characterization of papovavirus-and picornavirus-like particles in permanent pig kidney cell lines. Zentralblatt fur Bakteriologie, Parasitenkunde, Infektionskrankheiten und Hygiene Erste Abteilung Originale Reihe A: Medizinische Mikrobiologie und Parasitologie 1974, 226:153-167.

5. Saha D, Lefebvre DJ, Ducatelle R, Doorsselaere JV, Nauwynck HJ: Outcome of experimental porcine circovirus type 1 infections in mid-gestational porcine foetuses. BMC Vet Res 2011, 7:64.

6. Allan GM, Ellis JA: Porcine circoviruses: a review. J Vet Diagn Investig 2000 12:3-14.

7. Chae C: Postweaning multisystemic wasting syndrome: a review of aetiology, diagnosis and pathology. Vet J 2004, 168:41-49.

8. Chae C: A review of porcine circovirus 2-associated syndromes and diseases. Vet J 2005, 169:326-336.

9. Cino-Ozuna AG, Henry S, Hesse R, Nietfeld JC, Bai J, Scott HM, Rowland RR: Characterization of a new disease syndrome associated with porcine circovirus type 2 in previously vaccinated herds. J Clin Microbiol 2011, 49:2012-2016

10. Opriessnig T, Meng X-J, Halbur PG: Porcine circovirus type 2-associated disease: update on current terminology, clinical manifestations, pathogenesis, diagnosis, and intervention strategies. J Vet Diagn Investig 2007, 19:591-615.

11. Ramamoorthy S, Meng X-J: Porcine circoviruses: a minuscule yet mammoth paradox. Anim Health Res Rev 2009, 10:1-20

12. Kim J, Ha Y, Jung K, Choi C, Chae C: Enteritis associated with porcine circovirus 2 in pigs. Can J Vet Res 2004, 68:218-221.

13. Jung K, Kim J, Ha Y, Choi C, Chae C: The effects of transplacental porcine circovirus type 2 infection on porcine epidemic diarrhoea virus-induced enteritis in preweaning piglets. Vet J 2006, 171:445-450.
14. Opriessnig T, Madson DM, Roof M, Layton SM, Ramamoorthy S, Meng $X J$, Halbur PG: Experimental reproduction of porcine circovirus type 2 (PCV2)-associated enteritis in pigs infected with PCV2 alone or concurrently with Lawsonia intracellularis or Salmonella typhimurium. J Comp Pathol 2011, 145:261-270

15. Rose N, Opriessnig T, Grasland B, Jestin A: Epidemiology and transmission of porcine circovirus type 2 (PCV2). Virus Res 2012, 164:78-89.

16. Cooper JA: Effects of cytochalasin and phalloidin on actin. J Cell Bio/ 1987, 105:1473-1478.

17. Sorensen PM, lacob RE, Fritzsche M, Engen JR, Brieher WM, Charras G, Eggert US: The natural product cucurbitacin E inhibits depolymerization of actin filaments. ACS Chem Biol 2012, 7:1502-1508

18. Sun $X$, Whittaker GR: Role of the actin cytoskeleton during influenza virus internalization into polarized epithelial cells. Cell Microbio/ 2007, 9:1672-1682.

19. Lakadamyali M, Rust MJ, Babcock HP, Zhuang X: Visualizing infection of individual influenza viruses. Proc Natl Acad Sci U S A 2003, 100:9280-9285.

20. Bruce EA, Digard P, Stuart AD: The Rab11 pathway is required for influenza A virus budding and filament formation. J Virol 2010, 84:5848-5859.

21. Balmelli C, Steiner E, Moulin H, Peduto N, Herrmann B, Summerfield A, McCullough K: Porcine circovirus type 2 DNA influences cytoskeleton rearrangements in plasmacytoid and monocyte-derived dendritic cells. Immunology 2011, 132:57-65.

22. Duan D, Zhang S, Li X, Guo H, Chen M, Zhang Y, Han J, LV Y: Activation of the TLR/MyD88/NF-kappaB signal pathway contributes to changes in IL-4 and IL-12 production in piglet lymphocytes infected with porcine circovirus type 2 in vitro. PLoS One 2014, 9:e97653.

23. Misinzo G, Delputte PL, Lefebvre DJ, Nauwynck HJ: Porcine circovirus 2 infection of epithelial cells is clathrin-, caveolae- and dynamin-independent, actin and Rho-GTPase-mediated, and enhanced by cholesterol depletion. Virus Res 2009, 139:1-9.

24. Diesing AK, Nossol C, Danicke S, Walk N, Post A, Kahlert S, Rothkotter HJ, Kluess J: Vulnerability of polarised intestinal porcine epithelial cells to mycotoxin deoxynivalenol depends on the route of application. PLOS One 2011, 6:e17472.

25. Li W, Wang $X$, Ma T, Feng Z, Li Y, Jiang P: Genetic analysis of porcine circovirus type 2 (PCV2) strains isolated between 2001 and 2009: genotype PCV2b predominate in postweaning multisystemic wasting syndrome occurrences in eastern China. Virus Genes 2010, 40:244-251.

26. Carrascosa J, Carazo J, Carrascosa AL, García N, Santisteban A, Viñuela E: General morphology and capsid fine structure of African swine fever virus particles. Virology 1984, 132:160-172

27. Schierack $P$, Nordhoff M, Pollmann M, Weyrauch KD, Amasheh S, Lodemann U, Jores J, Tachu B, Kleta S, Blikslager A, Tedin K, Wieler LH: Characterization of a porcine intestinal epithelial cell line for in vitro studies of microbial pathogenesis in swine. Histochem Cell Biol 2006, 125:293-305.

28. Gassmann M, Focher F, Buhk HJ, Ferrari E, Spadari S, Hubscher U: Replication of single-stranded porcine circovirus DNA by DNA polymerases alpha and delta. Biochim Biophys Acta 1988, 951:280-289.

29. Tischer I, Peters D, Rasch R, Pociuli S: Replication of porcine circovirus: induction by glucosamine and cell cycle dependence. Arch Virol 1987, 96:39-57.

30. Taylor MP, Koyuncu OO, Enquist LW: Subversion of the actin cytoskeleton during viral infection. Nat Rev Microbiol 2011, 9:427-439.

31. Kirkham M, Parton RG: Clathrin-independent endocytosis: new insights into caveolae and non-caveolar lipid raft carriers. Biochimica et Biophysica Acta (BBA)-Mol Cell Res 2005, 1745:273-286.

32. Kalia M, Khasa R, Sharma M, Nain M, Vrati S: Japanese encephalitis virus infects neuronal cells through a clathrin-independent endocytic mechanism. J Virol 2013, 87:148-162.

33. Misinzo G, Meerts P, Bublot M, Mast J, Weingartl HM, Nauwynck HJ: Binding and entry characteristics of porcine circovirus 2 in cells of the porcine monocytic line 3D4/31. J Gen Virol 2005, 86:2057-2068.

34. Vincent IE, Carrasco CP, Guzylack-Piriou L, Herrmann B, McNeilly F, Allan GM, Summerfield A, McCullough KC: Subset-dependent modulation of dendritic cell activity by circovirus type 2 . Immunology 2005, 115:388-398. 
35. May JA, Ratan H, Glenn JR, Losche W, Spangenberg P, Heptinstall S: GPllb-Illa antagonists cause rapid disaggregation of platelets pre-treated with cytochalasin D. Evidence that the stability of platelet aggregates depends on normal cytoskeletal assembly. Platelets 1998, 9:227-232

36. Valderrama F, Cordeiro JV, Schleich S, Frischknecht F, Way M: Vaccinia virus-induced cell motility requires F11L-mediated inhibition of RhoA signaling. Science 2006, 311:377-381.

doi:10.1186/s12985-014-0193-0

Cite this article as: Yan et al: Infection of Porcine Circovirus 2 (PCV2) in

Intestinal Porcine Epithelial Cell Line (IPEC-J2) and Interaction between

PCV2 and IPEC-J2 Microfilaments. Virology Journal 2014 11:193.

\section{Submit your next manuscript to BioMed Central and take full advantage of:}

- Convenient online submission

- Thorough peer review

- No space constraints or color figure charges

- Immediate publication on acceptance

- Inclusion in PubMed, CAS, Scopus and Google Scholar

- Research which is freely available for redistribution 